\title{
A Long Contiguous Stretch of Homozygosity Disclosed a Novel STAG3 Biallelic Pathogenic Variant Causing Primary Ovarian Insufficiency: A Case Report and Review of the Literature
}

\author{
Simona Mellone ${ }^{1,+}+\mathbb{D}$, Marco Zavattaro ${ }^{2,+}{ }^{+}$Denise Vurchio ${ }^{3}$, Sara Ronzani ${ }^{3}$, Marina Caputo ${ }^{2,3}$, Ilaria Leone ${ }^{2}$, \\ Flavia Prodam ${ }^{2,3}$ and Mara Giordano ${ }^{1,3, *}$ \\ 1 Laboratory of Genetics, SCDU Biochimica Clinica, Ospedale Maggiore della Carità, 28100 Novara, Italy; \\ simona.mellone@uniupo.it \\ 2 Endocrinology, Department of Translational Medicine, University of Eastern Piedmont, 13100 Novara, Italy; \\ marco.zavattaro@med.uniupo.it (M.Z.); marina.caputo@uniupo.it (M.C.); 10033018@studenti.uniupo.it (I.L.); \\ flavia.prodam@med.uniupo.it (F.P.) \\ 3 Laboratory of Genetics, Department of Health Sciences, University of Eastern Piedmont, 13100 Novara, Italy; \\ denise.vurchio@uniupo.it (D.V.); sara.ronzani@uniupo.it (S.R.) \\ * Correspondence: mara.giordano@med.uniupo.it \\ + These authors contributed equally to this work and share first authorship.
}

Citation: Mellone, S.; Zavattaro, M.; Vurchio, D.; Ronzani, S.; Caputo, M.; Leone, I.; Prodam, F.; Giordano, M. A Long Contiguous Stretch of Homozygosity Disclosed a Novel STAG3 Biallelic Pathogenic Variant Causing Primary Ovarian Insufficiency: A Case Report and Review of the Literature. Genes 2021, 12, 1709. https://doi.org/10.3390/ genes12111709

Academic Editor: Peter Devilee

Received: 8 October 2021

Accepted: 26 October 2021

Published: 27 October 2021

Publisher's Note: MDPI stays neutral with regard to jurisdictional claims in published maps and institutional affiliations.

Copyright: (c) 2021 by the authors. Licensee MDPI, Basel, Switzerland. This article is an open access article distributed under the terms and conditions of the Creative Commons Attribution (CC BY) license (https:/ / creativecommons.org/licenses/by/ $4.0 /)$.

\begin{abstract}
Primary ovarian insufficiency (POI) refers to an etiologically heterogeneous disorder characterized by hypergonadotropic hypogonadism that represents a major cause of infertility in women under 40 years of age. Most cases are apparently sporadic, but about $10-15 \%$ have an affected first-degree relative, indicating a genetic etiology. Pathogenic variations in genes involved in development, meiosis and hormonal signaling have been detected in the hereditary form of the disorder. However, most cases of POI remain unsolved even after exhaustive investigation. A 19-year-old Senegalese female affected by non-syndromic POI presented with primary amenorrhoea and answered well to the hormonal induction of puberty. In order to investigate the presence of a genetic defect, aCGH-SNP analysis was performed. A $13.5 \mathrm{Mb}$ long contiguous stretch of homozygosity (LCSH) was identified on chromosome 7q21.13-q22.1 where the exome sequencing revealed a novel homozygous 4-bp deletion (c.3381_3384delAGAA) in STAG3. Pathogenic variants in this gene, encoding for a meiosis-specific protein, have been previously reported as the cause of POI in only eight families and recently as the cause of infertility in a male. The here-identified mutation leads to the truncation of the last 55 amino acids, confirming the important role in meiosis of the STAG3 C-terminal domain.
\end{abstract}

Keywords: STAG3; primary ovarian insufficiency; exome sequencing; LCSH

\section{Introduction}

Primary ovarian insufficiency (POI) is characterized by depletion of ovary follicles, leading to hypoestrogenism and hypergonadotropic hypogonadism, infertility and amenorrhea in women younger than 40 years [1,2]. This disorder represents one of the main causes of infertility affecting women, with a worldwide prevalence of approximately 1-3.7\% [3-5]. Women with POI may show a wide range of clinical phenotypes, from primary (PA) to secondary amenorrhea (SA) and other congenital or acquired abnormalities, and present either syndromic or isolated forms of the disease [6,7]. PA is usually diagnosed in adolescence in patients showing delayed puberty and absence of secondary sex characteristic development, while SA, which represents the most frequent POI phenotype, may occur at any age after menarche and is characterized by normal pubertal development $[8,9]$. Although POI is a heterogeneous disorder caused by iatrogenic, viral or autoimmune factors, more than $70 \%$ of cases remain idiopathic [1]. Chromosomal aberrations have long been recognized as a cause of POI and at least $10-13 \%$ of the syndromic cases present 
anomalies revealed by standard karyotype [10]. About $10-15 \%$ of women with POI have an affected first-degree relative and different modes of inheritance can be observed in families, suggesting the presence of several monogenic causes in the etiology of the disease [7]. To date, the use of different genomic approaches, including linkage studies, sequencing of candidate genes and whole exome sequencing (WES) allowed the identification of pathogenic alterations in more than 60 genes implicated in both syndromic and isolated POI [1-10]. Additionally, submicroscopic copy number variations (CNVs) encompassing genes potentially implicated in reproductive function have emerged as an important genetic determinant in POI [11]. The genes altered in POI encode for protein involved in DNA repair and meiosis [1] and pathogenic variants predispose to different forms of cancer [6,12-14]. Thus, the early diagnosis of the molecular mechanism underlying POI is essential to develop strategies for preventing the irreversible consequences on fertility, to improve clinical management and to perform genetic counseling with a long-term follow-up also considering tumor susceptibility.

Pathogenic variants in STAG3 (stromal antigen 3), which encodes a subunit of the cohesin complex participating to sister chromatid pairing during meiosis, have been identified as a rare POI monogenic cause. To date STAG3 biallelic variants have been reported in eight families worldwide, five of which were consanguineous pedigree $[6,8,13,15-19]$. All the affected women had isolated POI except for a patient belonging to a Palestinian family [6] who presented simultaneous bilateral ovarian tumors.

Here we report the identification of a novel biallelic pathogenic variation in STAG3 through a combined approach of CGH-SNP microarray and Clinical Exome Sequencing (CES) in a young Senegalese woman affected by non-syndromic POI.

\section{Materials and Methods}

\subsection{Case Presentation}

The patient was a 19-year-old female from Senegal, referred to the Emergency Room Department for dyspareunia and pelvic pain after her first sexual intercourse. She was also suffering from primary amenorrhea and anosmia. Familiar anamnesis revealed the absence of parental consanguinity. Computerized tomography (CT) investigation showed vaginal stenosis and failure to display ovaries. Physical examination showed absence of breast and pubic hair development, consistent with Tanner stage 1, although stature was normal for age. Hormonal profile was indicative of primary hypogonadism (17ß-estradiol $20 \mathrm{pg} / \mathrm{mL}$, FSH $88.1 \mathrm{mU} / \mathrm{mL}, \mathrm{LH} 28.7 \mathrm{mU} / \mathrm{mL}$ ), while the remaining pituitary function was preserved (TSH $1.4 \mu \mathrm{U} / \mathrm{mL}$, free-T $1.33 \mathrm{ng} / \mathrm{dL}$, prolactin $9.78 \mathrm{ng} / \mathrm{mL}$, GH $1.99 \mathrm{ng} / \mathrm{mL}$, IGF-I 271.8 $\mathrm{ng} / \mathrm{mL}, \mathrm{ACTH} 22.4 \mathrm{pg} / \mathrm{mL}, 8.00$ a.m. cortisol $11.7 \mu \mathrm{g} / \mathrm{dL}$ ). Further investigations revealed reduced bone mineral density at lumbar spine (Z-score -3.6$)$ and delayed hand bone age (14 years). Moreover, pelvic magnetic resonance (MR) confirmed the presence of a pre-pubertal uterus, characterized by hypoplasia $(38 \times 11 \times 19 \mathrm{~mm})$ and a fundus-to-cervix ratio of 1:1 (Figure 1, panel a,b). The cytogenetic analysis revealed a normal karyotype $(46, \mathrm{XX})$.

After hormonal and radiological diagnostic work-up, a puberty induction therapy using transdermal 17ß-oestradiol (estradiol hemyhidrate $25 \mu \mathrm{g} / 3$ days for 2 months, then $50 \mu \mathrm{g} / 3$ days) was started. After 3 months of treatment, the presence of pubic hair (P2) and breast development (B2), consistent with Tanner stage 2, were appreciable at physical examination. Six months since the beginning of puberty induction therapy, breast size and pubic hair further increased (B3 P3) and menarche occurred. Hormonal evaluation showed adequate 17B-oestradiol levels $(75 \mathrm{pg} / \mathrm{mL})$ and consensual reduction in gonadotropin concentration (FSH $4.7 \mathrm{mU} / \mathrm{mL}$, $\mathrm{LH} 0.4 \mathrm{mU} / \mathrm{mL}$ ). Treatment with transdermal estrogen led to oligomenorrhea and progressive pubertal development over the following months. After 24 months of therapy, complete pubertal (B5 P4) and uterine development occurred, and combined therapy with progesterone was started (Table 1). Pelvic magnetic resonance performed at that time revealed an anteverted-antiflex uterus of normal size and regular 
vaginal morphology; endometrial thickness was normal according to menstrual phase (Figure 1, panel c,d).

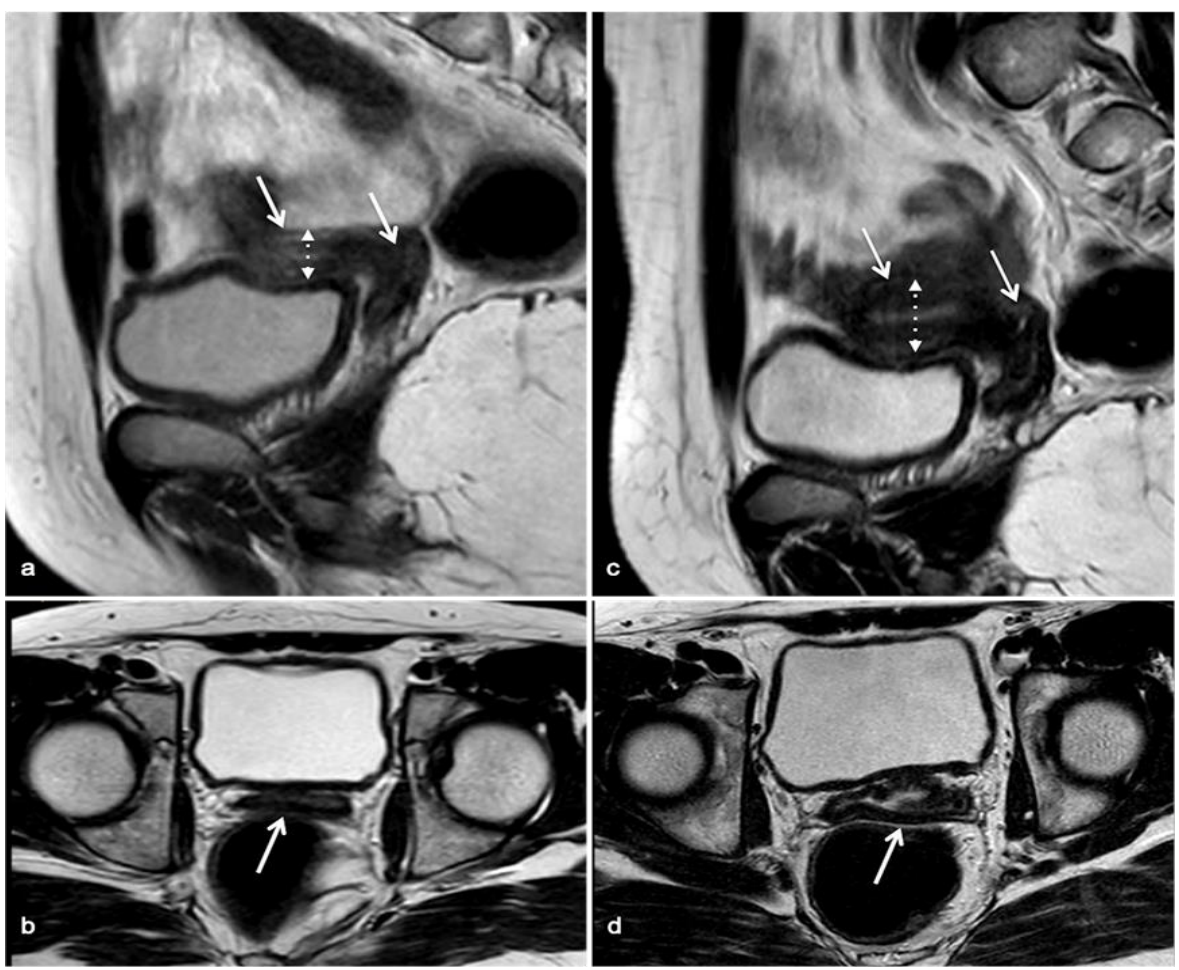

Figure 1. Magnetic resonance before and after estrogen replacement therapy. Panels " $a$ ", " $b$ " show uterine hypoplasia (continuous white arrows) in sagittal (panel " $a$ ") and transversal plane (panel “ $\mathbf{b}^{\prime \prime)}$. Reduced uterine thickness, consistent with pre-pubertal morphology, is evidenced in panel "a" (dashed arrow). In panels " $\mathrm{c}$ ", $\mathrm{d}$ ", continuous white arrows indicate the uterine development after 24 months of estrogen therapy both in sagittal (panel " $\mathrm{c}^{\prime \prime}$ ) and transversal (panel " $\mathrm{d}$ ") planes. Endometrial development and increase in uterine thickness are evident in panel " $\mathrm{c}$ " (dashed arrow).

Table 1. Hormonal and clinical changes over time of the described clinical case. B: breast; P: pubic hair; FSH: FollicularStimulating Hormone; LH: Luteinising Hormone.

\begin{tabular}{|c|c|c|c|c|c|c|}
\hline & $\begin{array}{c}\text { November } 2018 \\
\text { (Staring } \\
\text { Therapy) }\end{array}$ & $\begin{array}{c}\text { February } 2019 \\
\text { (+3 Months) }\end{array}$ & $\begin{array}{l}\text { May } 2019 \\
\text { (+9 Months) }\end{array}$ & $\begin{array}{l}\text { September } 2019 \\
\text { (+10 Months) }\end{array}$ & $\begin{array}{c}\text { June } 2020 \\
\text { (+18 Months) }\end{array}$ & $\begin{array}{c}\text { November } 2020 \\
\text { (+24 Months) }\end{array}$ \\
\hline Tanner stage (BP) & Stage $1(\mathrm{~B} 1, \mathrm{P} 1)$ & Stage $2(\mathrm{~B} 2, \mathrm{P} 2)$ & Stage 3 (B3,P2-3) & Stage $4(\mathrm{~B} 4, \mathrm{P} 3)$ & Stage $4(\mathrm{~B} 4, \mathrm{P} 4)$ & Stage $5(\mathrm{~B} 5, \mathrm{P} 4)$ \\
\hline $\begin{array}{c}17 \beta- \\
\text { oestradial }(\mathrm{pg} / \mathrm{mL})\end{array}$ & 20 & - & 75 & - & 27 & 40 \\
\hline $\mathrm{FSH}(\mathrm{mU} / \mathrm{mL})$ & 88.1 & - & 4.7 & - & 55.6 & 51.1 \\
\hline $\mathrm{LH}(\mathrm{mU} / \mathrm{mL})$ & 28.7 & - & 0.4 & - & 24.2 & 29.9 \\
\hline Menstrual cycle & Amenorrhea & Amenorrhea & Menarche & Oligomenorrhea & Euhenorrhea & Oligomenorrhea \\
\hline $\begin{array}{c}\text { Therapy } \\
\text {-oestradial } \\
\text { hemyhidrate } \\
\text {-progesterone }\end{array}$ & $25 \mu \mathrm{g} / 3$ days & $50 \mu \mathrm{g} / 3$ days & $50 \mu \mathrm{g} / 3$ days & $50 \mu \mathrm{g} / 3$ days & $50 \mu \mathrm{g} / 3$ days & $\begin{array}{c}50 \mu \mathrm{g} / 3 \text { days } \\
100 \mathrm{mg} / 14 \text { days }\end{array}$ \\
\hline
\end{tabular}

\subsection{CGH-SNP Microarray Analysis}

Genomic DNA of the proband was extracted from peripheral blood through the ReliaPrep Blood gDNA Miniprep System (Promega), according to the manufacturer's recommendation. Medium-density microarray analysis was performed using standard pro- 
tocols with a GenetiSure Dx Postnatal Array $4 \times 180 \mathrm{~K}+$ SNP (Agilent Technologies, Santa Clara County, CA, USA). The SNP array contains 59,000 single-nucleotide polymorphism probes and 107,000 oligonucleotide probes (60-mer) with a resolution of $5 \sim 10 \mathrm{Mb}$ for $\mathrm{ROH}$ (Region of Homozygosity) detection. The slides were scanned through Agilent SureScan Dx Microarray Scanner System (Agilent Technologies, USA). Image analysis, normalization and annotation were based on Agilent Feature Extraction Software. Finally, CNVs were called with Agilent CytoDx Software 1.1.1.0 using tiff images from data.

\subsection{Clinical Exome Sequencing(CES)}

The Agilent SureSelect Custom Constitutional Panel $17 \mathrm{Mb}$ (Agilent, Santa Clara, CA, USA) that includes 5227 clinically relevant genes was used for the preparation of the library. This custom panel also covers all 65 genes from the Genomics England Panel App for primary ovarian insufficiency (https:// panelapp.genomicsengland.co.uk/ accessed on 26 October 2021). Exon-enriched library was subjected to a $150 \mathrm{bp}$ paired-end sequencing on the Illumina MiSeq platform (Illumina, San Diego, CA, USA). Sequencing reads passing quality filters were aligned to the human reference genome build (GRGh37/hg19) and variant calling was performed using the SureCall v3.5 software (Agilent Technologies). Then VCF files were annotated with the wANNOVAR tool. After that, the variants were filtered and prioritized using a personalized bioinformatics pipeline: variants with a read coverage of less than $5 \times$ and a Qscore of below 20 were filtered out; an allele frequency in public databases $<0.1 \%$ (1000 Genomes, the ESP cohort data set, GnomAD, Exome Aggregation Consortium) was considered; synonymous variants were excluded. For the missense variants, we used at least four in silico prediction tools (SIFT, CADD, Polyphen, MutationTaster) through the Varsome website (https:/ /varsome.com/ accessed on 26 October 2021) [20].

\subsection{Sanger Sequencing}

The STAG3 variant (NM_001282716.1:c.3381_3384delAGAA) (p.Glu1128Metfs*42) identified by clinical-exome sequencing was validated by Sanger sequencing using the following primers designed by the Primer3 (v. 0.4.0) software: forward: $5^{\prime}$-TTGGAAAGAGAG CACACCTG-3' ${ }^{\prime}$ and reverse: $5^{\prime}$-TGGTGTTAATGGGGAGAAAA- $3^{\prime}$.

\section{Results}

An array CGH-SNP assay was used as first tier test to investigate the presence of both DNA copy number variations (CNVs) and loss of heterozygosity ( $\mathrm{LOH}$ ) regions. No chromosomal unbalance was identified. However, the aCGH-SNP revealed a LCSH (long contiguous stretches of homozygosity) region of $13.5 \mathrm{Mb}$ (from rs2374083 to rs1990167) on chromosome 7q21.13-q22.1. A LCSH refers to a disomic long homozygous stretch and is used here instead of $\mathrm{LOH}$ as the latter describes an event where heterozygosity was originally present and now is lost. This region contained 127 OMIM genes (Figure 2A) among which the best candidate to explain the patient's phenotype was STAG3, whose biallelic mutations had been previously detected in patients with autosomal recessive POI $[6,8,13,15-19]$.

Due to the large size of STAG3 (34 exons) and to eventually disclose pathogenic variants in other genes a NGS platform including 5227 genes (Agilent SureSelect Custom Constitutional Panel 17) involved in human genetic disorders (Clinical Exome) was used to identify the causative molecular defect. The average sequencing depth was $77 \mathrm{x}$ with $96.93 \%$ of the target sequence covered at $\geq 20 \times, 89.27 \%$ covered at $\geq 50 \times$ and $70.52 \%$ covered at $\geq 100 \times$. The variants obtained from CES were filtered as previously described and confirmed the presence of a LCSH on chromosome 7q21.13-q22.1. A variant at the homozygous state in exon 30 of the STAG3 gene was identified, namely c.3381_3384delAGAA (NM_001282716.1; Figure 2B), then validated by Sanger sequencing. This 4-bp deletion (NC_000007.13:g.99808776_99808779del) causes a frameshift with the introduction of a premature stop codon (p.Glu1128Metfs ${ }^{*} 42$ ) resulting in a predicted truncated protein of 1170 amino acids (wild-type STAG3 protein: 1225 amino acids). The variant was not present 
in the public databases and was classified as pathogenic according to the American College of Medical Genetics and Genomics (ACMG) standards and guidelines for the interpretation of variations (criteria: PVS1, PM2, PP3) [21]. We did not find any other pathogenic or likely pathogenic homozygous variant in genes involved in POI or in other that passed through the set filters $(<0.1 \%$ in population databases, $>20$ Q score and $>5 \times$ coverage), consequently STAG3 (p.Glu1128Metfs*42) was considered the best disease-causing candidate variant in this patient. Sanger sequencing confirmed the homozygous variant in the patient's DNA. Unfortunately, the parents' DNA was not available to investigate the origin of this LCSH.

(A)

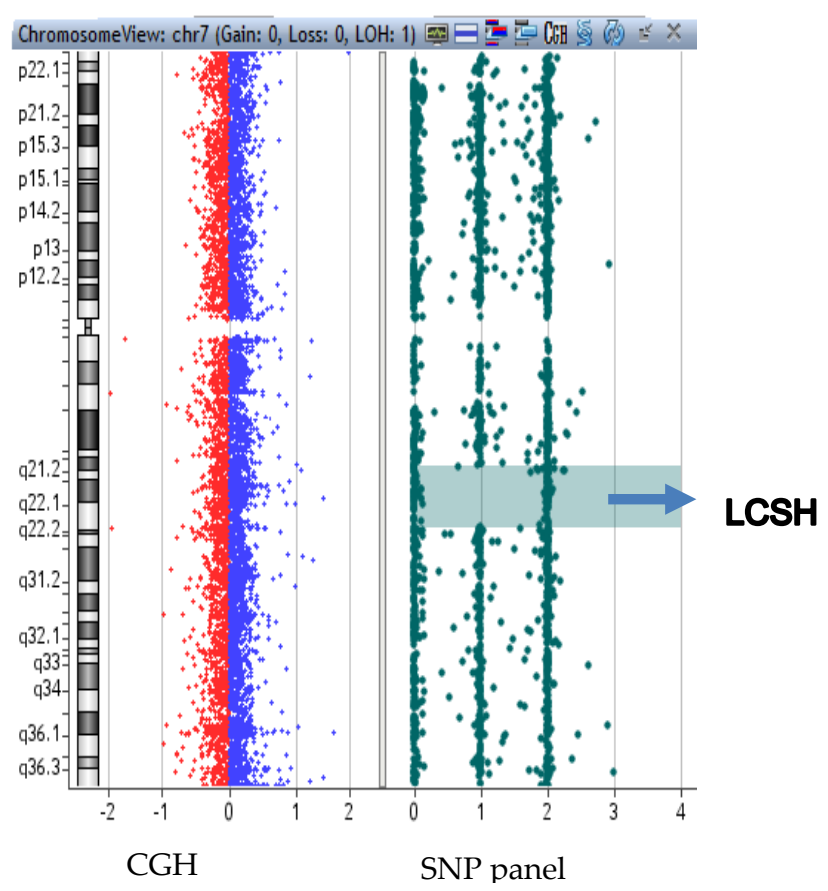

(B)
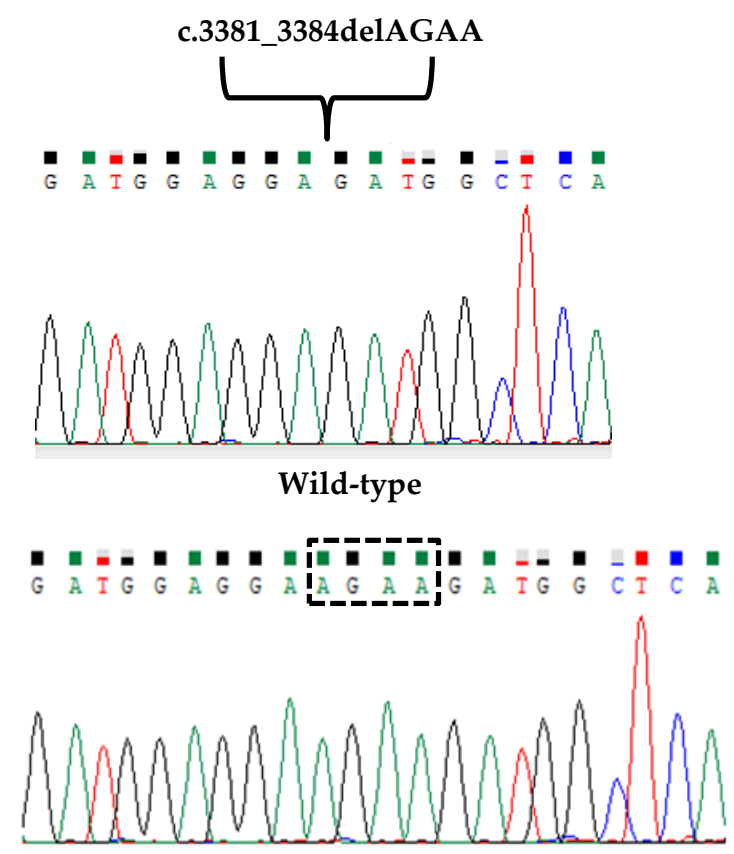

Figure 2. CGH-SNP array and sequencing results. (A) Array-CGH-SNP results: the LCSH on chromosome 7q21.13-q22.1 is indicated by a blue arrow. (B) The partial sequencing electropherogram is shown including the novel homozygous mutation identified in STAG3 (NM_001282716.1:c.3381_3384del); the corresponding wild-type sequence is shown below with a dashed rectangle showing the deleted bases.

\section{Discussion and Conclusions}

POI is an extreme heterogeneous disorder caused by pathogenic variations in genes involved in germ cell development, oogenesis, folliculogenesis, steroidogenesis and hormone signaling [22]. Chromosomal unbalances detected through standard karyotype as well as submicroscopic alterations are involved in syndromic forms of POI [10]. Ledig et al. [23] reported the identification of several micro-rearrangements detected through aCGH in 74 German POI patients, encompassing several genes involved in meiosis, DNA repair and folliculogenesis.

In the present patient a platform combining aCGH and SNP array was used as the first-tier genetic test. In addition to $\mathrm{CNVs}$, this platform detects the presence of homozygosity regions through SNP genotyping as the consequence of (i) hemizygosity caused by a CNV, that can be simultaneously confirmed by CGH probes; (ii) autozygosity of identity-by-descent regions underlying the presence of a putative recessive disorder; and (iii) uniparental disomy (UPD) when the homozygosity is confined to a chromosomal region (or to entire chromosome) underlying an imprinting disorder. In the patient described here, the CGH-SNP array revealed a normal female karyotype and the presence of a unique interstitial long contiguous stretches of homozygosity region (LCSH) of $13.5 \mathrm{Mb}$ 
on chromosome 7q21.13-q22.1. Besides the 7q LCSH, no other large regions ( $>5 \mathrm{Mb}$ ) of homozygosity were detected, indicating either segmental UPD [24] or a distant shared parental ancestry. The origin of this LCSH might have been explored through the parents' DNA, which was not available as both father and mother currently live in Senegal.

The best candidate in the LCSH region was STAG3, which has been previously associated with a recessive form of POI consistent with the patient's phenotype. STAG3 encodes a subunit of the multiprotein cohesin complex required during meiosis I for homologous chromosome pairing, correct synapsis and segregation of chromosomes, proper recombination and DNA repair [25]. In mammals, meiosis-specific cohesin subunits include a SMC1 subunit (SMC1 $\beta$ ), two additional $\alpha$-kleisins (RAD21L and REC8) and a stromal antigen protein (STAG3) that are specifically expressed in meiosis. Moreover, Stag3 specifically localizes on the spindle apparatus and is required for microtubule stability and spindle assembly to preserve the euploidy in the mouse eggs [26].

Females Stag3 ${ }^{-/-}$mice lack ovarian follicles indicating a severe ovarian dysgenesis [27] and also develop ovarian tumors as observed in humans [6]. It is likely that homozygous or compound heterozygous variants in STAG3 may also affect male fertility due to the early prophase I arrest and apoptosis in both sex germ cells. Indeed, all Stag3 ${ }^{-/-}$ male mice described to date are infertile $[28,29]$ and a biallelic loss-of-function STAG3 variant has been recently reported in infertile males [28-30] affected by complete bilateral meiotic arrest.

Up to date, only 11 variants in STAG3 have been reported as genetic causes of POI in eight pedigrees (Figure 3) $[6,8,13,15-19]$ with a predicted loss of function effect in most cases. The STAG3 frameshift variant identified here is a 4-bp deletion in exon 30 and the resulting transcript would either undergo nonsense-mediated decay [31] or result in a truncated protein devoid of the C-terminal domain similarly to a previously described frameshift mutation truncating the last 206 C-terminal residues in exon 28 [13]. The Cterminal domain is specific of STAG3 as it is not conserved neither in STAG1 nor in STAG2, which belong to the same family but are involved in somatic cell division [32]. As STAG3 is specifically expressed during meiosis $[6,13]$ the effect of the variant identified here on protein/mRNA level could not be performed. However as the variant does not fall in the last exon of the transcript, it can be hypothesized that RNA nonsense mediated decay may occur in vivo.

The finding of two POI patients with pathogenic variants truncating the C-terminal can support an important specific role of this domain of STAG3 during meiosis.

Our patient presented with primary amenorrhea, absence of breast development, hypoplasia of the uterus, osteoporosis and normal height. These clinical features were also reported in other individuals carrying STAG3 pathogenic variants $[6,8,13,15-19]$. The hormone replacement therapy (HRT) allowed for puberty to be induced and for the patient to achieve complete secondary sexual characteristics, adequate growth, uterine development and menstrual fluxes. HRT currently represent the mainstay therapy for women with POI and plays a pivotal role in reducing long-term comorbidities (e.g., osteoporosis and cardiovascular disease) and improving sexual health by restoring normal serum estrogen concentrations according to age $[3,9,33]$.

Taken together, our observations strength the importance of a correct diagnosis and clinical management in women with POI. The diagnostic workflow should include the molecular test with multi-gene panel including STAG3 to allow an appropriate ovarian monitoring in the long-term follow-up, considering the high risk to develop ovarian tumors. 


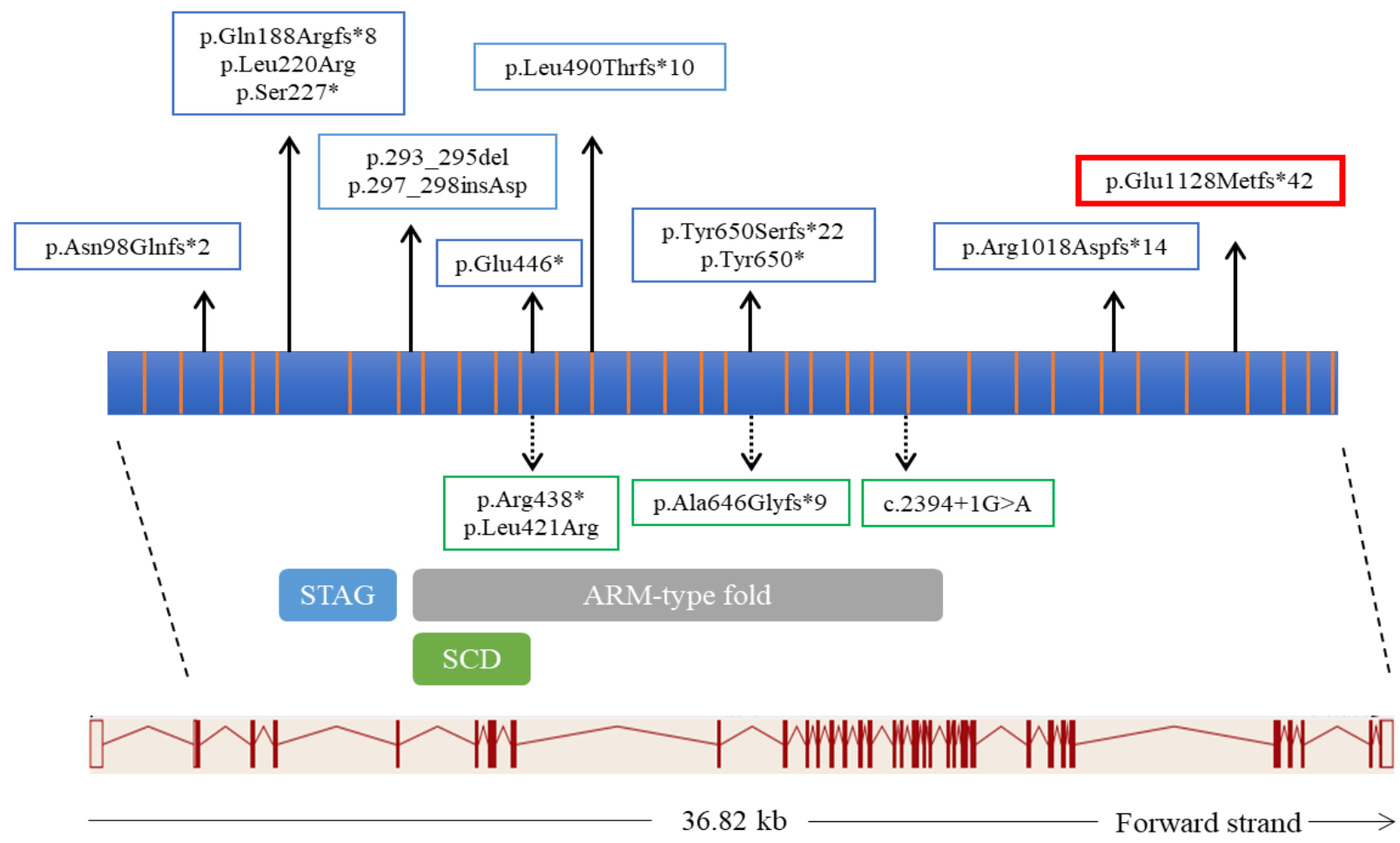

Figure 3. Schematic representation of STAG3 and protein structure with pathogenic variants reported in POI patients. The exon-intron structure of STAG3 (transcript NM_001282716.1) is displayed in the lower part of the figure. The scheme of STAG3 protein consisting of 1225 amino acids (aa) (protein domains for ENSP00000400359.1) is reported in the middle part of the figure with colored rectangles indicating the STAG domain (174-283 aa; PF08514 Pfam database), an Armadillo-type fold domain (ARM-type fold) (303-813 aa; SSF48371 Superfamily database) and a Stromalin conservative domain (SCD) (309-394 aa; PS51425 Prosite profiles). The pathogenetic variants identified in previous studies in females are shown in blue boxes whereas the variant identified in this study is shown in the red box. The pathogenetic variants identified in males are shown in green boxes.

Author Contributions: M.G. and F.P.: conception and coordination of the work and drafted the article; S.M.: acquisition, analysis and interpretation of data; D.V., S.R.: performing of genetic tests; M.Z., M.C., I.L.: clinical assessment and management of the patient; S.M. and M.Z. participated in writing the manuscript. All authors have read and agreed to the published version of the manuscript.

Funding: Fondi Vari: Dipartimento di Scienze della Salute, Università del Piemonte Orientale.

Institutional Review Board Statement: This study was carried out in accordance with the recommendations of our hospital "A.O.U. Maggiore della Carità, Novara" with written informed consent from the patient.

Informed Consent Statement: Written informed consent was obtained from the patient for publication of this Case report and accompanying images. A copy of the written consent is available for review by the Editor of this journal.

Data Availability Statement: Not applicable.

Acknowledgments: We acknowledge the technical staff of the laboratory of Genetics (SCDU). Biochimica Clinica, Ospedale Maggiore della Carità, and the patient's family for the cooperation.

Conflicts of Interest: The authors declare no conflict of interest.

\section{References}

1. Huhtaniemi, I.; Hovatta, O.; La Marca, A.; Livera, G.; Monniaux, D.; Persani, L.; Heddar, A.; Jarzabek, K.; Laisk-Podar, T.; Salumets, A.; et al. Advances in the Molecular Pathophysiology, Genetics, and Treatment of Primary Ovarian Insufficiency. Trends Endocrinol. Metab. 2018, 29, 400-419. [CrossRef] [PubMed]

2. Nelson, L.M. Clinical practice. Primary Ovarian Insufficiency. N. Engl. J. Med. 2009, 360, 606-614. [CrossRef] 
3. Shelling, A.N. Premature ovarian failure. Reproduction 2010, 140, 633-641. [CrossRef]

4. Tucker, E.J.; Grover, S.R.; Bachelot, A.; Touraine, P.; Sinclair, A.H. Premature Ovarian Insufficiency: New Perspectives on Genetic Cause and Phenotypic Spectrum. Endocr. Rev. 2016, 37, 609-635. [CrossRef]

5. Golezar, S.; Tehrani, F.R.; Khazaei, S.; Ebadi, A.; Keshavarz, Z. The global prevalence of primary ovarian insufficiency and early menopause: A meta-analysis. Climacteric 2019, 22, 403-411. [CrossRef]

6. Caburet, S.; Arboleda, V.; Llano, E.; Overbeek, P.; Barbero, J.L.; Oka, K.; Harrison, W.; Vaiman, D.; Ben-Neriah, Z.; García-Tuñón, I.; et al. Mutant Cohesin in Premature Ovarian Failure. N. Engl. J. Med. 2014, 370, 943-949. [CrossRef]

7. Rossetti, R.; Ferrari, I.; Bonomi, M.; Persani, L. Genetics of primary ovarian insufficiency. Clin. Genet. 2016, 91, 183-198. [CrossRef]

8. França, M.M.; Nishi, M.Y.; Funari, M.F.; Lerario, A.M.; Baracat, E.C.; Hayashida, S.A.; Maciel, G.A.; Jorge, A.A.; Mendonca, B.B. Two rare loss-of-function variants in the STAG3 gene leading to primary ovarian insufficiency. Eur. J. Med. Genet. 2018, 62, 186-189. [CrossRef] [PubMed]

9. Webber, L.; Davies, M.; Anderson, R.; Bartlett, J.; Braat, D.; Cartwright, B.; Cífková, R.; Keizer-Schrama, S.D.M.; Hogervorst, E.; Janse, F; et al. ESHRE Guideline: Management of women with premature ovarian insufficiency. Hum. Reprod. 2016, 31, 926-937. [CrossRef]

10. Qin, Y.; Jiao, X.; Simpson, J.L.; Chen, Z.-J. Genetics of primary ovarian insufficiency: New developments and opportunities. Hum. Reprod. Updat. 2015, 21, 787-808. [CrossRef]

11. Jaillard, S.; Akloul, L.; Beaumont, M.; Hamdi-Roze, H.; Dubourg, C.; Odent, S.; Duros, S.; Dejucq-Rainsford, N.; Belaud-Rotureau, M.A.; Ravel, C. Array-CGH diagnosis in ovarian failure: Identification of new molecular actors for ovarian physiology. J. Ovarian Res. 2016, 9, 63. [CrossRef] [PubMed]

12. AlAsiri, S.; Basit, S.; Wood-Trageser, M.; Yatsenko, S.A.; Jeffries, E.P.; Surti, U.; Ketterer, D.M.; Afzal, S.; Ramzan, K.; Haque, M.F.-U.; et al. Exome sequencing reveals MCM8 mutation underlies ovarian failure and chromosomal instability. J. Clin. Investig. 2014, 125, 258-262. [CrossRef]

13. Heddar, A.; Dessen, P.; Flatters, D.; Misrahi, M. Novel STAG3 mutations in a Caucasian family with primary ovarian insufficiency. Mol. Genet. Genom. 2019, 294, 1527-1534. [CrossRef]

14. Wood-Trageser, M.; Gürbüz, F.; Yatsenko, S.A.; Jeffries, E.P.; Kotan, L.D.; Surti, U.; Ketterer, D.M.; Matic, J.; Chipkin, J.; Jiang, H.; et al. MCM9 Mutations Are Associated with Ovarian Failure, Short Stature, and Chromosomal Instability. Am. J. Hum. Genet. 2014, 95, 754-762. [CrossRef]

15. Colombo, R.; Pontoglio, A.; Bini, M. A STAG3 missense mutation in two sisters with primary ovarian insufficiency. Eur. J. Obstet. Gynecol. Reprod. Biol. 2017, 216, 269-271. [CrossRef]

16. He, W.-B.; Banerjee, S.; Meng, L.-L.; Du, J.; Gong, F.; Huang, H.; Zhang, X.-X.; Wang, Y.-Y.; Lu, G.-X.; Lin, G.; et al. Whole-exome sequencing identifies a homozygous donor splice-site mutation inSTAG3that causes primary ovarian insufficiency. Clin. Genet. 2017, 93, 340-344. [CrossRef]

17. Stabej, P.L.Q.; Williams, H.; James, C.; Tekman, M.; Stanescu, H.C.; Kleta, R.; Ocaka, L.; Lescai, F.; Storr, H.; Bitner-Glindzicz, M.; et al. STAG3 truncating variant as the cause of primary ovarian insufficiency. Eur. J. Hum. Genet. 2015, 24, 135-138. [CrossRef]

18. Xiao, W.-J.; He, W.-B.; Zhang, Y.-X.; Meng, L.-L.; Lu, G.-X.; Lin, G.; Tan, Y.-Q.; Du, J. In-Frame Variants in STAG3 Gene Cause Premature Ovarian Insufficiency. Front. Genet. 2019, 10, 1016. [CrossRef]

19. Demain, L.A.; Boetje, E.; Edgerley, J.J.; Miles, E.; Fitzgerald, C.T.; Busby, G.; Beaman, G.M.; O'Sullivan, J.; O'Keefe, R.T.; Newman, W.G. Biallelic loss of function variants in STAG3 result in primary ovarian insufficiency. Reprod. Biomed. Online 2021, 16, S1472-S6483. [CrossRef]

20. Kopanos, C.; Tsiolkas, V.; Kouris, A.; Chapple, C.E.; Aguilera, M.A.; Meyer, R.; Massouras, A. VarSome: The human genomic variant search engine. Bioinformatics 2018, 35, 1978-1980. [CrossRef]

21. Richards, S.; Aziz, N.; Bale, S.; Bick, D.; Das, S.; Gastier-Foster, J.; Grody, W.W.; Hegde, M.; Lyon, E.; Spector, E.; et al. Standards and guidelines for the interpretation of sequence variants: A joint consensus recommendation of the American College of Medical Genetics and Genomics and the Association for Molecular Pathology. Genet. Med. 2015, 17, 405-423. [CrossRef]

22. França, M.M.; Mendonca, B.B. Genetics of Primary Ovarian Insufficiency in the Next-Generation Sequencing Era. J. Endocr. Soc. 2019, 4, bvz037. [CrossRef]

23. Ledig, S.; Röpke, A.; Wieacker, P. Copy Number Variants in Premature Ovarian Failure and Ovarian Dysgenesis. Sex. Dev. 2010, 4, 225-232. [CrossRef]

24. D'Amours, G.; Langlois, M.; Mathonnet, G.; Fetni, R.; Nizard, S.; Srour, M.; Tihy, F.; Phillips, M.S.; Michaud, J.L.; Lemyre, E. SNP arrays: Comparing diagnostic yields for four platforms in children with developmental delay. BMC Med. Genom. 2014, 7, 70. [CrossRef]

25. Hopkins, J.; Hwang, G.; Jacob, J.; Sapp, N.; Bedigian, R.; Oka, K.; Overbeek, P.; Murray, S.; Jordan, P.W. Meiosis-Specific Cohesin Component, Stag3 Is Essential for Maintaining Centromere Chromatid Cohesion, and Required for DNA Repair and Synapsis between Homologous Chromosomes. PLoS Genet. 2014, 10, e1004413. [CrossRef]

26. Zhang, M.; Dai, X.; Sun, Y.; Lu, Y.; Zhou, C.; Miao, Y.; Wang, Y.; Xiong, B. Stag3 regulates microtubule stability to maintain euploidy during mouse oocyte meiotic maturation. Oncotarget 2016, 8, 1593-1602. [CrossRef]

27. Winters, T.; McNicoll, F.; Jessberger, R. Meiotic cohesin STAG 3 is required for chromosome axis formation and sister chromatid cohesion. EMBO J. 2014, 33, 1256-1270. [CrossRef] [PubMed] 
28. Riera-Escamilla, A.; Enguita-Marruedo, A.; Moreno-Mendoza, D.; Chianese, C.; Sleddens-Linkels, E.; Contini, E.; Benelli, M.; Natali, A.; Colpi, G.M.; Ruiz-Castañé, E.; et al. Sequencing of a 'mouse azoospermia' gene panel in azoospermic men: Identification of RNF212 and STAG3 mutations as novel genetic causes of meiotic arrest. Hum. Reprod. 2019, 34, 978-988. [CrossRef]

29. Tüttelmann, F.; Ruckert, C.; Röpke, A. Disorders of spermatogenesis: Perspectives for novel genetic diagnostics after 20 years of unchanged routine. J. Med. Genet. 2018, 30, 12-20. [CrossRef]

30. van der Bijl, N.; Röpke, A.; Biswas, U.; Wöste, M.; Jessberger, R.; Kliesch, S.; Friedrich, C.; Tüttelmann, F. Mutations in the stromal antigen 3 (STAG3) gene cause male infertility due to meiotic arrest. Hum. Reprod. 2019, 34, 2112-2119. [CrossRef]

31. Vivenza, D.; Godi, M.; Faienza, M.F.; Mellone, S.; Moia, S.; Rapa, A.; Petri, A.; Bellone, S.; Riccomagno, S.; Cavallo, L.; et al. A novel HESX1 splice mutation causes isolated GH deficiency by interfering with mRNA processing. Eur. J. Endocrinol. 2011, 164, 705-713. [CrossRef] [PubMed]

32. Zhang, N.; Jiang, Y.; Mao, Q.; Demeler, B.; Tao, Y.J.; Pati, D. Characterization of the Interaction between the Cohesin Subunits Rad21 and SA1/2. PLoS ONE 2013, 8, e69458. [CrossRef] [PubMed]

33. Gelbaya, T.; Vitthala, S.; Nardo, L.; Seif, M. Optimizing hormone therapy for future reproductive performance in women with premature ovarian failure. Gynecol. Endocrinol. 2010, 27, 1-7. [CrossRef] 